\title{
COMPUTERIZED INFORMATION PROCESSING IN THE PRIVATE HOUSEHOLD: FIRST OUTLOOK ON BUSINESS IMPACTS
}

\author{
Walter Brenner \\ Lutz Kolbe
}

\begin{abstract}
There is a particular tendency to identify the private household as a significant target group for technology and content providers. The high relevance of an interdisciplinary treatment of this subject for business, science and politics is obvious. The residential applications for the household can be subdivided into several main types, all of which are based on a common technological infrastructure. In the near future a huge market potential will arise from the converging markets of information processing, telecommunication and consumer electronics. This will have an impact in the home and will lead to an innovative supply of products and services restructuring and will change the matters of private life. The article emphazises the strategic importance of the "Computerized Information Processing in the Private Household" (CIPHo) for business administration and information technology.
\end{abstract}

\section{INTRODUCTION}

More and more aspects of daily life are being affected by the creation of new information and communication technologies (ICT) or the upgrading of existing domestic applications. The American government's Data Highway Initiative (Press Secretary, 1993) indicates that creating the infrastructure to extend the scope of information processing into the private home is a global challenge. In Europe, the "Bangemann Report" recently presented at the Corfu summit of the European premier ministers aims at a strategic European Information Infrastructure (European Commission, 1994; Europaeische Kommission, 1994). The question of regulation or deregulation of markets is only a single aspect in our "information society".

We use the term "Computerized Information Processing in the Private Household (CIPHo)" to refer to all the information technology and telecommunication applications that private persons might make use of in their homes, on journeys, or in public. 
In this article the first section gives an overview of the current trends central to information technology for the private household. The second section provides a framework for the future information technology infrastructure and applications for the home. The third part then examines possible future infrastructures for the private household presenting two specific cases. Finally, the strategic implications for the business sphere are considered by describing the different roles of market players.

\section{CURRENT TRENDS}

To understand the implications of this quite unknown research field we have to clear up the underlying trends. At least five mainstreams can be identified:

\section{Information highway}

The discussion about the computerized information processing in the private household gains in importance by the emergence of the "information highway" or the "infobahn" idea which means an overall supply of information to everybody. One of the main objectives is the construction of access ramps to new sources of information using fibre technology or hybrid fibre-coax approaches to the home or neighborhood. Another goal is a plethora of new telematic services offered to private users such as interactive games or customized news (Reinhard, 1994; Dernbach, 1993).

\section{Converging markets and strategic alliances}

This "data highway" is forced by an obvious tendency in the development of markets, namely the consumer electronics, the computer and the telecommunication markets (OECD, 1992). New challenges like the above-mentioned interactive services cannot be provided only by one of the market players. Know-how from various types of businesses is needed to implement such services. In order to face this problem there are two current paths: Companies are trying to diversify making mergers and aquisitions such as the Viacom-Paramount deal in the US. Thereby they want to ensure their competence in telecommunication, content and service. The other way is to build strategic alliances. This path is often used where each player is strong enough to compete alone but is willing to participate in synergy. $\Lambda \mathrm{n}$ example is the alliance of Time Warner and Silicon Graphics in the field of interactive TV.

\section{Interactivity, individualization and specialization}

Along with enhanced multimedia presentation and manipulation features (HighText, 1993) comes the increasing wish for interactivity. The private user no longer wants to consume from the TV screen or be isolated with his home PC. He or she wants to get in touch with the environment. According to this feature, the services have to provide a certain extent of individualization to the user. They can reach from local news from the neighborhood to completely individual ones compiled on given patterns (Brand, 1990). The future aim of the Information Highway is to have one personal channel to every home and a back channel enabling interaction with the head-end. This trend is supported by the specialization of information content. The target groups are highly segmented to personal, socio-economic or local criteria. For example there is an increasing number of special interest TV channels, e.g. exclusively for weather or travel (Goet7, 1994). 


\section{Communication instead of pure information}

In the last 10 years the processing of pure information was of main interest to the market players. Now the view has changed: The central questions are now where the required information is located, how to obtain it and how to get it to the point of request. In other words the communication era is on (Philips, 1994). The example of the "Personal Intelligent Communicator" describes this situation. This explains why the telecommunication sector becomes more and more important. The high penetration rates of telephone and cable TV connections are a welcome installed base for home-oriented services.

\section{Standard home devices and "killer applications"}

There are two main areas of concern in the field of computerized information processing in the private home: The first one deals with the infrastructures and the second one with the services. Concerning the infrastructure the providers try to evaluate whether the PC or the TV will be the standard home device for the future. Both devices have their pros and cons. It may be that today's computer with TV expansion and the TV set with computer enhancements (set-top box) will lead to one hybrid device for all purposes like the modern copier-phone-fax-answering-devices (Reinhardt, 1994). All providers of content are hesitating to invest feeling a strong uncertainty about the type of application which will be first widely accepted by the households, the so-called "killer application." Short-term profits are expected from the games sector, but the potentials for the long-term, e.g. by interactive TV, have not been assessable so far.

\section{FRAMEWORK FOR THE CIPHO}

This section provides a framework for Computerized Information Processing in the Private Household (see Figure 1).

\section{Information technology infrastructure for the private household}

In future the private household will be linked via networks to an environment from which it obtains services. This infrastructure can be subdivided into two significant areas (see Figure 1): the in-home and out-of-home infrastructures (Brenner \& Kolbe, 1994).

In-home infrastructure. The in-home infrastructure consists of all the hardware, software and networks that are installed within the private houschold.

- Home Networks provide the basic framework for the entire future in-home infrastructure (see the "intelligent home" concept) by the linking of the various components via powerful, standardized "household networks." In addition to the standardization of diverse networks, integration is central to this (EHSA, 1992).

- Hardware that is relevant to information processing in the private household is characterized by a high degree of specialization: the $C D$ player is used to listen to music and the television for viewing. As well as innovative product ideas and improvements to existing products, a tendency towards combing existing and new functionalities can be observed (e.g. the CDi Player from Philips) (IEEE, 1992).

- Software currently available to the private household is aimed, with the exception of computer games, at business users. Developments in this area will lead to a set of "standard software for the private household" which is characterized by its multimedia nature and intuitive user interfaces (Microsoft, 1992). 


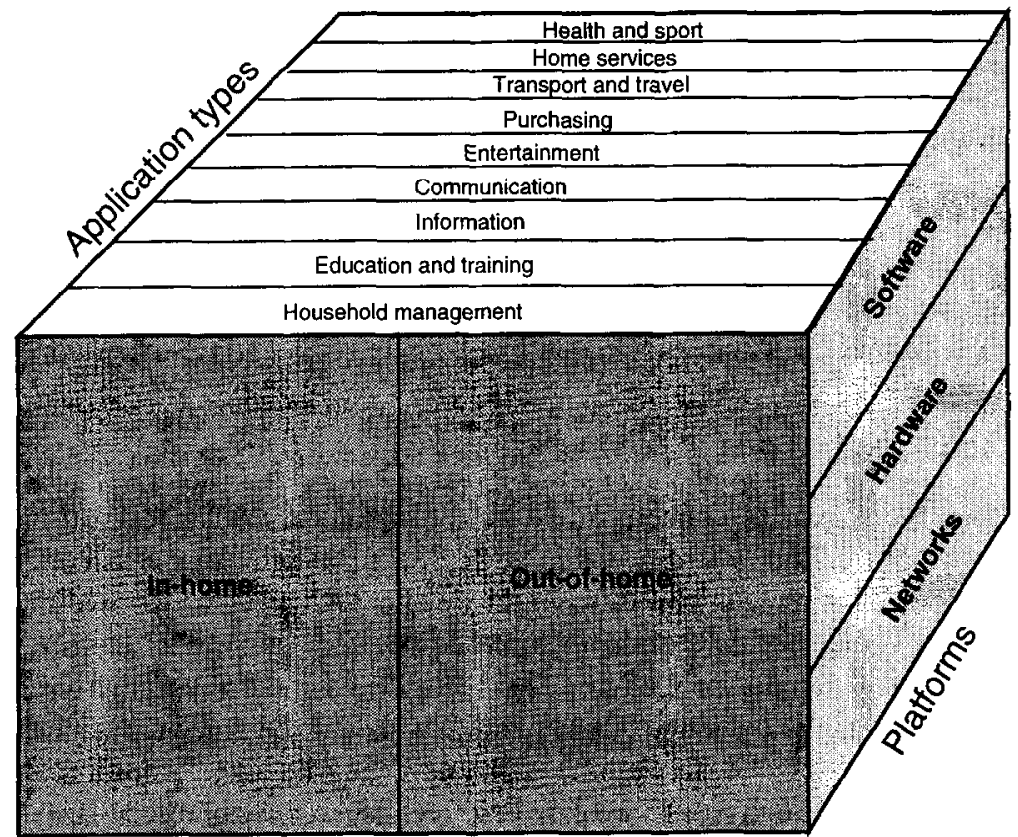

Types of infrastructures

Figure 1. Framework for the computerized information processing in the private household.

Out-of-home infrastructure. The out-of-home infrastructure consists of the hardware, software and networks that are installed outside the private household but which the private household can take advantage of in order to use components of the in-home infrastructure effectively, and thereby gain access to new services.

- Networks belonging to the out-of-home infrastructure constitute the link between the private household and the environment by means of which data can be transported to and from the household. As well as improvements in the transmission media (glass-fibre instead of copper), the ATM broadband communication offers new performance for the private household (Armbruester, 1993).

- Hardware from the out-of-home infrastructure creates the platform for the provision of services that can be accessed by the private household. It includes central architecture hardware such as multimedia servers for video-on-demand systems, or mobile communication equipment (Silicon Graphics, 1993).

- Software in the out-of-home infrastructure can be subdivided into two important areas: communication systems for network services, and database systems as storage locations for the growing mass of increasingly multimedia data (General Magic, 1994c).

\section{Taxonomy of computerized applications for the private household}

Given the foundation provided by the basic infrastructure, we now consider cxamples of computerized information processing that indicate in concrete terms how the in-home and out-of-home technologies can be employed to implement a specific application (see Figure 1). We identify nine basic types (Brenner \& Kolbe, 1994):

(i) Health and Sport refers to all applications concerned with making provision for, maintaining and monitoring people's health. They include personal 
monitoring systems, as well as analysis and advice systems (Miles, 1988).

(ii) Home Services consist of systems that support home security, cooking, heating and cooling, lighting and washing. Of particular significance are systems for energy management and surveillance of rooms and buildings (Jeck, 1993).

(iii) Transport and Travel comprises all applications that support the selection, preparation and undertaking of journeys. The planning of journeys can be supported by electronic catalogues, just as travel itself is assisted by tourist information and traffic monitoring systems (Loedel, 1992).

(iv) Purchasing relates to all activities involved in the selection, advice, payment and handling of purchases for the private household. Teleshopping, which opens up new purchasing possibilities for households, deserves particular mention (eShop, 1994).

(v) Entertainment includes those applications that can be used for leisure activities or for the purpose of entertaining members of the household. Of particular significance for the future potential in this area are new possibilities, e.g. by interactive television (AT\&T, 1993).

(vi) Communication using computerized applications enables the private household to establish bi-lateral or multi-lateral contact with the immediate or wider environment. Electronic discussion and advice forums meet the household's need for social contact and exchange (Philips, 1994).

(vii) Information is offered by all services in which the dissemination of news or other information to the private household is central. New media, such as electronic books, are in increasing use (Brand, 1990).

(viii) Education and Training will, in an increasingly dynamic private and career environment, gain in importance. The use of new media together with the geographical independence of teachers and students, and the universal availability of knowledge will make a significant contribution to the potential in this area (ISDN Report. 1994).

(ix) Household Management combines all the administrative functions of the private household, such as the management of private book-keeping, or the payment of bills. As in business, these can be more efficiently structured using computerized support (Neue Mediengesellschaft, 1994).

\section{TWO EXAMPLES OF ICT FOR THE PRIVATE HOUSEHOLD}

The framework of in- and out-of-home infrastructures and applications for residential information processing is now illustrated by means of two case studies.

\section{New television: The case of Time Warner's full service network}

One of the most cited examples (see also AT\&T, 1993) is the interactive TV trial of Time Warner Cable, the second largest cable TV operator in the US, and Silicon Graphics together with other partners in Orlando, Florida. About 4000 households will be involved in this pilot which began its initial phase at the end of 1994. In comparison to other projects, this Full Service Network (FSN) (see Figure 2) is very ambitious because of its advanced technology and extensive realization of different applications (Time Warner, 1993; Ziemer, 1994; Goetz, 1994).

Definition of interactive TV. Up to now there is no widely accepted definition about what "interactive TV" really means. Four levels of interactivity can be differentiated (Hightext, 1993a): 


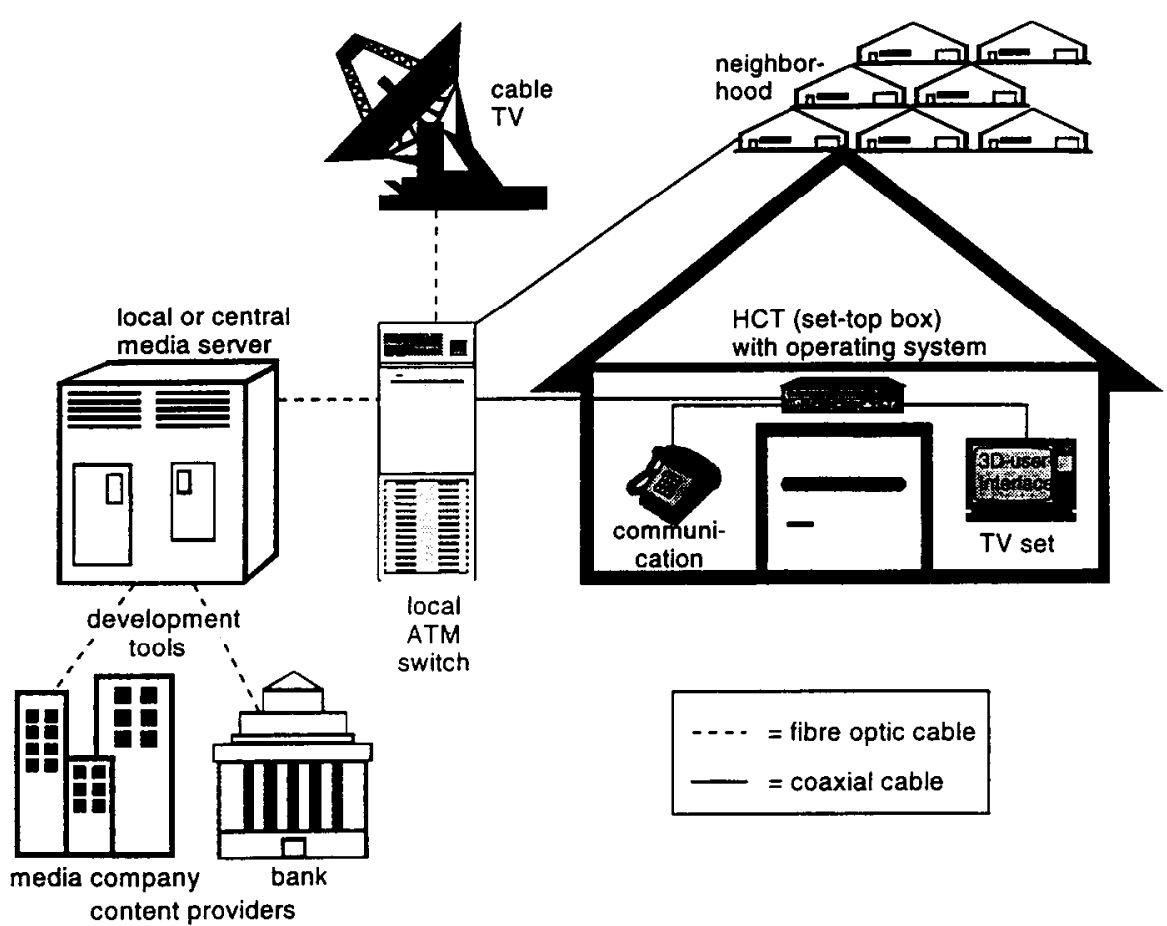

Figure 2. The Orlando full service network.

- Level 1: Modified programs. Two or more channels show the same program, but under different conditions, e.g. different points of view, or with actors of different color.

- Level 2: Additive $T V$. In addition to the analog program, digital information can be downloaded, e.g. a route map complementary to a travel show.

- Level 3: Media on demand. The household is able to access digital audio or video information whenever it wants to.

- Level 4: Fully Communicative TV. The consumer on the one hand makes use of interactive services (e.g. shopping) and on the other hand they interact with other households, e.g. by video phone, or the content itself, e.g. interactive motion pictures.

What is unique to the Orlando pilot is that it tries to implement applications on all levels.

Infrastructure. According to the infrastructure framework an interactive TV-network like the FSN (see Figure 2) employs the following components (Silicon Graphics, 1993; Silicon Graphics, 1994, Sattler, 1994; Reinhardt, 1994):

(i) In-home hardware. Set-top boxes or home communication terminals (HCT) have the main purpose of decompressing digital video and audio streams into analog signals for the TV set. But besides this they have the capability for picture processing, security functions (decoding) and real-time video under a multitasking operating system. The Orlando HCT is based on a Silicon Graphics Indy Workstation with $100 \mathrm{MHz}$ CPU and 24 Bit graphics. Other hardware providers like Toshiba and Scientific Atlanta are involved, too. The price for such a "tele-computer" should be reduced from today's workstation price to $\$ 300$ by the year 1997 . 
(ii) In-home software. The interactive user-interface has been designed to be extremely simple and intuitive, even more than the actual interfaces on PCs. The Orlando trial uses a graphical interface with real-time 3D animation of real world objects. The consumer manipulates, for example the video, like the real VCR device with known buttons and functions. The presentation of offered videos is made by rotating, $3 \mathrm{D}$ video cassettes with well-known covers from the video library. The decentralized operating system in the HCT manages the access to local and remote content. It has to support two methods of information download: first information from different providers for specific services on a central media server and second access to completely different content servers via a standard gateway. Therefore the operating system in the set-top box has to be flexible, scalable, open and based on standards.

(ii) Out-of-home hardware. The requirements for the media server exceed those for the HCT by far. Thousands of data streams have to be managed, the connections to be updated, accounts to be rewritten, access requests to be verified and the whole media library to be handled. On request the waiting time for the user may not be more than one or two minutes otherwise the services won't be accepted. Even the simultaneous access of many users to different versions of the same data, e.g. the same video, has to be solved. The huge amount of storage necessary for digital video information ( 50 films need about $100 \mathrm{~GB}$ ) requires a sophisticated hierarchical memory system. In Orlando a Silicon Graphics Challenge video server with massively-parallel technology from MIPS Technologies and digital TV enhancements is used.

(iv) Out-of-home software. Another important component of the Full Service Network is a set of development tools for the providers of content. They can have their own media servers and deliver the information through the cable operator's network subject to all regulations of protocols and exchange standards. The other method is sharing the expensive servers. Being open to all suppliers third-party providers only have to use the development tool to generate fully compatible applications.

(v) Network topology. The interactivity and multimedia data streams require high bandwidth and low response times. Time Warner has decided to use a hybrid fibre-coax network. The central data flows are directed on fibre optic trunks to blocks of 500 households where the further distribution to the single property continues on coax TV-cable (fibre to the neighborhood, see Figure 2). The transmission protocol is the fast-packet asynchronous transfer mode (ATM) that combines flexibility like bandwidth on demand with high performance of continuous bit rates. The ATM equipment like the switch unit moving information with $20 \mathrm{GBit} / \mathrm{s}$ is provided by AT\&T Network Systems.

Applications for Orlando FSN. A lot of services are planned to be tested during the Orlando trial. Somc of them arc alrcady in place clscwhere, c.g. teleshopping, but nowhere are they realized simultaneously and under the utilization of this advanced technology. The following is a brief description of several of the possible services (Time Warner, 1993):

- Alternative Access - Competitive access for homes and businesses to longdistance telephone service, bypassing the local exchange.

- Distance Learning -- Interactive educational instruction that allows full-motion television coverage of the participants in a classroom exercise to be transmitted 
between two or more locations. Real-time or digitally stored courses are available for homes as well.

- Interactive Games - Video games that are accessed by the consumer from central digital storage and can be played with any other user in the system. Eventually, the games will be full motion video and three dimensional.

- Interactive Shopping - Offers customers random access to full motion video of a wide range of merchandise, with immediate ordering by remote keypad.

- PCS - Personal communication service. A mini cellular voice service using inexpensive instruments. The cells are interconnected using the local coaxial and fibre network.

- Picture Phone - Telephone service offering full motion video of the parties displayed on a standard television screen.

- Video-on-Demand - A service allowing each customer immediate access to hundreds of movies and other programs. Features include pause, rewind and fast-forward functions.

- Video Conferencing - A business conferencing service offering full motion video displaying participants from two or more sites.

\section{New communication: The case of General Magic}

The new future-oriented type of personal ICT combines known information processing capabilities with communication features. It meets the requirements of the modern whole-person communication, i.e. the user has an increasing need to remember (internal talk-like ideas), to communicate (maintainance of relationships) and to know (information-related services) (Philips, 1994; General Magic, 1994b).

History. General Magic, a spin-off of Apple Computers and now a joint venture of companies including AT\&T, Matsushita, Motorola, Philips, Sony and Toshiba, started in 1990 with the mission to create new personal intelligent communications products and services by developing and licensing technology. The result was the development of Telescript, a communications and networking language, and Magic Cap, the software tools that provide the icon-driven interface (see Figure 3) and the development environment (General Magic, 1994b). All these parts of infrastructure, as proposed above, employ the concept of communicating applications. They enable the user to communicate with remote service providers in any number of ways: to exchange messages by e-mail, to access information such as news or to transact business with on-line stores. For example, if you want to fly to Barcelona you simply have to specify the essentials like date, time or price category. The Telescript intelligent agents move through the network, exchange information with those of service agencies and finally propose a list of airlines to you which will fulfill your specification.

\section{Infrastructure.}

(i) In- and out-of-home hardware: Mobile PIC devices. Infrastructure providers like Sony, Philips or Motorola have developed a pocket-sized hardware device similar to Apple's "Newton Notepad". In the first quarter of 1994 Motorola released its "Envoy" as the first one. In contrast to Personal Digital Assistants (PDA) they are called Personal Intelligent Communicators (PIC) emphasizing the built-in enhanced communication features by intelligent software agents (General Magic, 1994c). Communications are currently facilitated via the public telephone net, maybe through a regular phone or a special version into which the PIC can 


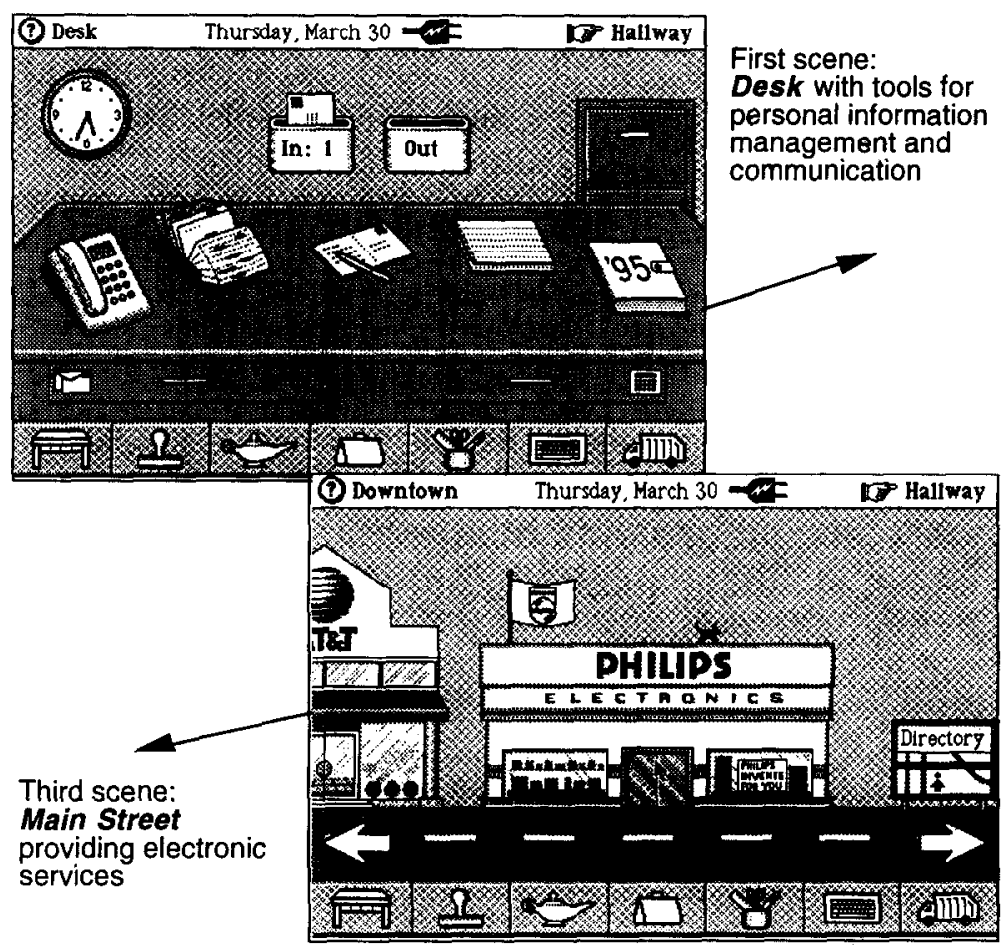

Figure 3. User-interface of General Magic Cap.

be docked. In the future, wireless PICs will be available and the user will be able to take them as mobile telephones as well.

(ii) In-home software. The Magic Cap (Communicating Applications Platform) interface runs on communication-based products. It has Telescript technology as the basis for its communication architecture and provides the user with smart stationery, envelopes and intelligent mailboxes. The Magic Cap software is no genuine operating system. Although it can run natively on personal intelligent communicators, it can also work as an application under Windows or Macintosh system on personal computers. It consists of three basic metaphors (General Magic, 1994a,b). The opening scene in the Magic Cap interface is the desk (see Figure 3) where you find packages associated with communications, organization and personal management. The principal desktop applications are telephone, address book, messages, notebook and datebook. The scene is extensible for additional packages from independent developers. The scene that resides beyond the desk inside the house is the hallway. Here reside doors where users can enter rooms. Each room has a particular function, for instance, a game room is where users may download and save games available from other content providers. The library is where users keep reference information and files. The hallway is extensible as well and can be customized to the user. The third scene is downtown or the main street (see Figure 3) - a visualization of the world outside your home - where users can access a variety of information and transaction services supplied by independent developers. Downtown is an extensible area, i.e. content or service providers can rent a property in the street and place their respective icon (building) there. By tapping the icon the building is entered, i.e. the service is accessed. All scrvices are 
communicating applications. The user will be able to assemble his own main street composed of favorite electronic suppliers.

(iii) Out-of-home software. Telescript is to communication what Postscript is to printing: An environment in which messages, like documents, are active programs, not just passive data. Telescript includes an object-oriented, interpreted programming language with which software developers can build communicating applications. They provide intelligent agents that move through networks connecting computers and personal communicators. Telescript technology is implemented as a portable interpreter, called a Telescript engine.

(iv) Network management. Telescript comprises three integral components (General Magic, 1994a, General Magic, 1994c) enabling the communication and network management: Active programming elements, so-called agents, can transport themselves to other locations in the network and can interact with other agents. These agents serve as "extensions" of the specific application in various machines within the network. The component go initiates the communication between agents and places by transporting agents across the network. The last Telescript programming object is place acting as a venue in which agents can meet and interact with other agents.

Generally speaking, this concept uses existing network infrastructure, but shifts the intelligence from the computing hardware to a "smart net principle" by building virtual exchange zones.

Applications for the PIC. A number of companies in the US have already announced their intention to support the Magic Cap platform by providing content or applications. The first that will have been installed will be the AT\&T PersonaLink Services. They were created to take advantage of the Telescript technology to provide members with smart messaging services and give them access to the electronic marketplace. America Online Inc. has set up a special version of its on-line services for Magic Cap users. It gives access to international e-mail and via Internet to Prodigy or CompuServe and other services, e.g. news or stock quotes. eShop Inc. is building a set of on-line stores for the Magic Cap system using compelling visual merchandizing (eShop, 1994) whereas Intuit offers its product "Pocket Quicken" for personal financial organization aimed at the mobile user. Mead Data Central Inc. will provide a number of services applying AT\&T PersonaLink. One is the sending of daily news summaries to the customer. Another is a customized information service by which short summaries of articles on 300 topics out of thousands of news sources can be received. News Electronic Data Inc. is building a travel-related service that includes maps where addresses, hotels and restaurants are highlighted and routes between fixed points are constructed. The service even informs the customer about the weather conditions in the chosen part of the map.

\section{A MODEL OF STRATEGIC IMPLICATIONS FOR MARKET PLAYERS}

A simple but useful five-layer model (sec Figure 4) for the market of ICT in the private household (adapted from Sattler, 1994) should serve as a tool for research as well as for competitors to define their own position and to realize the other market players in order to carry out strategic plans.

One of the greatest criticisms of the "information highway" idea is the reproach that everything is only supply-side driven and neglects completely the consumers needs and wants (see Figure 4). This is the reason why many trials have failed. New technology 


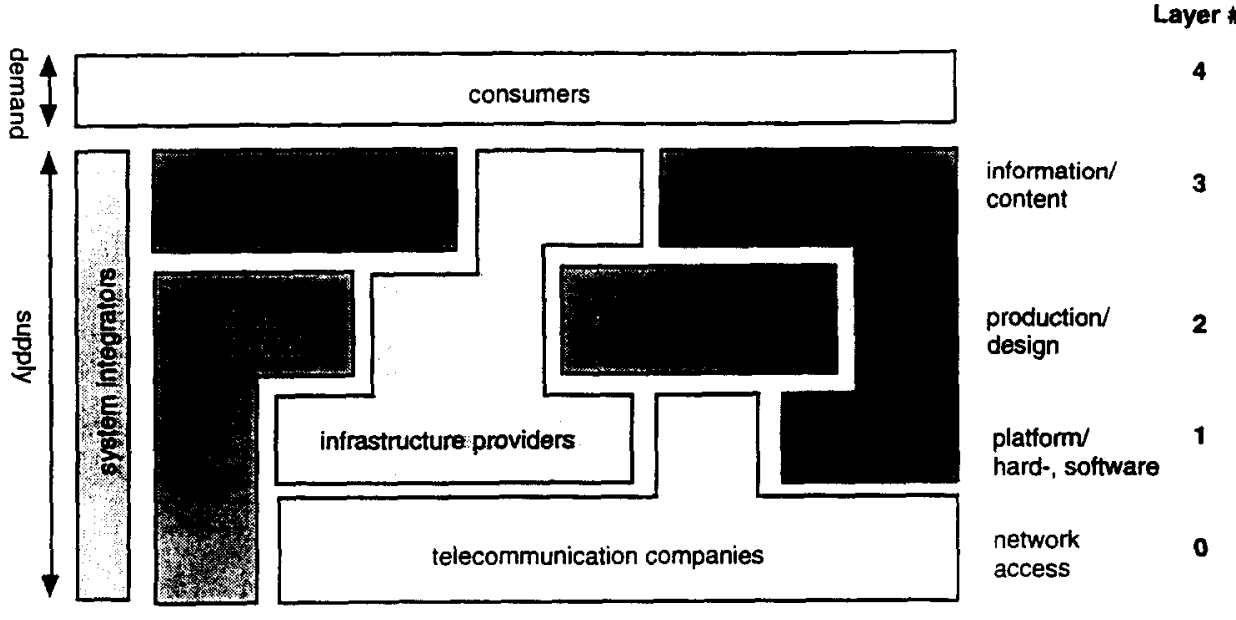

Figure 4. Model of market players.

is not enough to provide a good buyer-oriented service. There are some basic observations which should be considered when planning home-ICT products (Van Rijn, 1988).

\section{Demand side: distinctive rationalism}

The consumer in the private household shows behavior patterns which are completely different from those of organizations. The process of buying and spending the budget doesn't follow such rational rules in terms of a cost-benefit analysis or RoI optimization. The goods and services are bought for a life time and should deliver short-term pleasure. While in organizations there is training and professional installation of systems, services at home have to be "plug-and-play" without studying a thick manual. The observed behavior of a purchaser in business and at home is different: for instance, being a technological freak he or she buys the latest, just-released devices, but in the firm such criteria as supplier reliance and proven quality are more decisive. From this we learn that the "economics of private households" are a crucial element on the way to a successful concept of home-ICT.

The question central to provision of home-ICT to households is the examination of factors being essential for acceptance of consumers (Sattler, 1994; Christoffersen, 1994). Three fundamental critical success factors are to be mentioned:

- User-interface: The interaction and the acceptance the consumer will show depends on an interface that is easy to learn, intuitive to handle and fun to work with. Multimedia elements and graphical environments are mandatory.

- Price: The private customer has to be motivated to reallocate his fixed amount of time and dispensable income for the new services. One can only succeed in gaining acceptance if the new technology is cheap enough for mass consumption, e.g. $\$ 300$ for a set-top box instead of $\$ 3000$ now. This is possible by low introductory prices expecting high future demand or by subsidizing the initial hardware costs by the usage fee.

- Needs and wants: So far nobody really knows what kind of application the consumer would like to use. The success of one or two services - the "killer applications" - will make the pace for subsequent ones. The definition of needs represents the imagination of content providers of what the household would like, e.g. the banks provide home-banking. But this is not sufficient: in some 
countries like Switzerland there is no big want for such a service because the paper-based banking has been perfectly optimized. Only if needs and wants are matched will the service be successful.

For further research the consumers layer 4 (see Figure 4) can easily be micro-segmented into a more subtle structure. However, this is left out due to the focus on the market players.

\section{Supply side:}

The other perspective on the market of home-oriented ICT is the supply-side. The suppliers can be sub-divided into seven groups (see Figure 4). Some of these groups are not mutually exclusive and a clear distinction in today's diversified companies is very difficult to make (Christoffersen, 1994; Sattler, 1994; Goetz, 1994).

One group of participants in the market is the content providers. They solely contribute their information and data (layer 3 ) to the service managed and constructed by someone else. Examples are a publishing company or a news agency which provides the content for electronic newspapers - as the Washington Post does for an interactive TV trial of Bell Atlantic and Oracle in Virginia. They are responsible only for the content of the telematic service. On the whole, they are less affected by the new technology because they are still working with the same information in electronic form.

One layer below, there are the agencies dealing with the production, design and shaping of information content (layer 2). Agencies like the Munich-based Very Activity obtain the content from the content providers and arrange the shape of content that it is suitable for broadcast or other ways of distribution to the customer. Examples are media consultants or marketing agencies. The range of services is quite broad from creation to translation into multimedia environments.

A group with strong influence on other players is the one of media companies. They include not only information and content but also the design layer. In addition to their domain, they have competence in the sector of hard- and software infrastructure, e.g. the Bertelsmann AG with companies like Telemedia or BMG Ariola Multimedia. This means that they are able to offer turn-key solutions from data to delivery for a given application (without the network). Their market power derives from the strong effectiveness and efficiency arising from the synergy of all three elements.

The infrastructure providers, e.g. Philips or Microsoft, serve the same layers of competence - platforms, design and content - as the media companies, but their main area is the development and selling of hard- and software products to the private user, mainly coming from the consumer electronics direction. They have often had the experience that in competitive markets the hardware doesn't determine the profit margins but the provision and shaping of information. So they diversified from platforms (layer 1) to the more content-oriented levels (layers 2-3) as the example of Sony's Electronic Publishing Company proves.

A company that owns content, e.g. a mail-order company, instructs a service provider to manage the whole process of design, choice of appropriate platforms, billing and access to the network. Though not having network facilities of its own the service provider negotiates contracts with the telecommunication company. Service providers are often spin-offs of telecommunication companies or joint venture firms like the Media Service $\mathrm{GmbH}$, a common enterprise of Bertelsmann AG, the Kirch group - the main German owner of movie rights - and German Telecom (meanwhile banned by the European antitrust law). 
The mightiest market players are the telecommunication companies. They have the facilities for network access on cable, telephone lines or terrestrial transmission. Every other player has to use their networks to get in touch with the end-user. For instance, in the US there is competition between different telco companies on a private market (OECD, 1992; Reinhardt, 1994). In Europe, e.g. in Germany, monopolies draw a considerably different picture of the situation. So the model has to be interpreted a little differently according to cultural contexts. In the US telco companies are not only limited to network (layer 0 ) and strongly connected platform provision (layer 1), but they are also involved in the profitable content business (see Viacom and its merger with Paramount).

System integrators unite all supply-side layers $0-3$. The most difficult part of supply, the network access, is often solved by strategic alliances or acquisitions. This is regularly limited to huge multi-national companies with outstanding backgrounds as the example of Time Warner reveals. Only a few companies world-wide are capable of providing this all-round service.

An advanced, more complex version of the model might consider the interaction of the different players, an in-depth analysis of the consumers' role or a modification depending on the European, American or Asian culture.

\section{CONSEQUENCES}

The high level of households' penetration with entertainment and home installation equipment can be used as a starting point for evolution: there are development areas for business in the implementation of both infrastructure and applications (Europaeische Kommission, 1994). We need new understanding about the three main sectors being mostly affected by the emergence of computerized information processing in the home:

- Business Administration: Big market potentials are to come out of infrastructures and applications for the home. New models for planning, implementation and controlling in business have to be applied. Existing product lines, business units and strategic plans should be reviewed or redefined for home-ICT (Brenner \& Kolbe, 1994).

- Society and Policy-making: We are now on the way to the "information society." Not only the working place is changing, but the domestic sphere is affected as well and will change essentially the shape of society. Therefore politics - not only in the US (Press Secretary, 1993) - must identify this topic as crucial and discuss whether financial or executive activities are indicated.

- Legislation: The provision of interactive services like home-shopping requires, e.g. in Germany, a fundamental change of the status quo in legislation. "Is this normal broadcasting of general interest or only electronic services for a special target group?" and "Who is in charge of the control of content, subject to what kind of laws?" are two of many unsolved questions. The deregulation of the market for telecommunication by supra-national initiatives (European Commission, 1994; Reinhardt, 1994) will strike the so far existing monopolies and have its impact on the private customer.

Once models and prototypes for the ICT infrastructures and its applications have been developed, the central concern must be the definition of strategic plans within the cnterprise to take advantage of the huge market potentials. 


\section{REFERENCES}

Armbruester, H. (1993). Die Flexibilitaet von ATM: Unterstuetzung kuenftiger Netzdienste, Multimediaund Mobilkommunikation. In Nachrichtentechnik u. Elektronik, part 1, March, part 2, May.

AT\&T Corporation (Ed.) (1994). VCTV: A Video-On-Demand Market Test, AT\&T Technical Journal, 93.

European Commission (Ed.) (1994, May 26). Recommendations to the European Council: Europe and the global information society, Brussels.

Brand, S. (1990). Media Lab-Computer, Kommunikation und Medien, Hamburg.

Brenner, W. \& Kolbe, L. (1994). Future Business Spheres Arising from Computerized Information Processing in the Private Household. Proceedings of HOIT, Copenhagen.

Christoffersen, M. (1994). User needs and telecommunication service provision in Denmark, Paper presented at the IFIP Working Group 9.3, Copenhagen, June 27.

Dernbach, C. (1993). Report Datenautobahnen-Politikum Kommunikation, MACup, 12.

EHSA (European Home Systems Assoziation) (Ed.) (1992, March 15). Home Systems Specification, ESPRIT Projekt 5448.

eShop Inc. (Ed.) (1994, January). eShop offers first electronic shopping technology, Press Release, San Mateo.

Europaeische Kommission (Ed.) (1994). Wachstum, Wettbewerbsfaehigkeit, Beschaeftigung. Herausforderungen der Gegenwart und Wege ins 21. Jahrhundert, Weissbuch, Luxemburg.

Goetz, G. (Ed.) (1994). Fernsehen 2000: Global, digital, interaktiv, Special issue of Kabel \& Satellit.

Hightext (Ed.) (1993a, June 9). TV interaktiv - Hintergrunddienst fuer das interaktive Fernsehen, Muenchen.

Hightext (Ed.) (1993b), multiMEDIA - Informationsdienst fuer Medienintegraion, 3(12).

IEEE Consumer Electronics Society (Ed.) (1992). IEEE Transactions on Consumer Electronics, 37(2), Special Issue on Home Systems.

Wird das virtuelle Klassenzimmer bald Realitaet? (1994). ISDN Report p. 19.

Jeck, S. (1993). Technologie im Haushalt 2010, Praxisarbeit an der Wissenschaftlichen Hochschule fuer Unternehmensfuehrung. Otto-Beisheim-Hochschule: Vallendar.

Loedel, D. et al. (1992). Elektronische Produktkataloge -- Entwicklungsstand und Einsatzmoeglichkeiten. Wirtschaftsinformatik, 34(5).

Gencral Magic (Ed.) (1994a). Glossary, Mountain Vicw.

General Magic (Ed.) (1994b). Magic Cap Means Communication: Magic Cap, Mountain View.

General Magic (1994c). Apples Antwort auf den Newton, MACup, 2.

Neue Mediengesellschaft GmbH Ulm (Ed.) (1994, February). BTX Magazin, 2.

Microsoft Corporation (Ed.) (1992). Encarta, Multimedia Encyclopedia, Redmond.

Miles, I. (1988). Home Informatics, Information Technology and the Transformation of Everyday Life, London.

Press Secretary of the White House (Ed.) (1993). National Information Infrastructure - The Agenda for Action, Tab. A-Tab. G, Washington.

OECD (Ed.) (1992). Telecommunication and Broadcasting: Convergence or Collision, Paris.

Philips (Ed.) (1994). Whole-person communications: a new vision.

Reinhardt, A. (1994, March). Building The Data Highway, Byte International Edition, pp. 46-74.

Sattler, C. (1994, May 5-6). Von Fernsehverteildiensten zu interaktiven Videodiensten auf Abruf, Communication Highway, IIR-Conference, Frankfurt/Main.

Silicon Graphics (Ed.) (1993, June 7). Time Warner selects Silicon Graphics to develop key technologies for interactive digital cable TV, News Release.

Silicon Graphics (Ed.) (1994, March). Interaktive Digitale Netzwerke: Die naechste grosse technologische Revolution, Press Release.

Time Warner Cable (Ed.) (1993, May). The Full Service Network, Iime Warner Cable's Vision of our Telecommunications Future, News Release.

Van Rijn, F., \& Williams, R. (1988). Concerning Home Telematics, Proceedings of the IFIP TC 9, Amsterdam.

Ziemer, A. (Ed.) (1994). Digitales Fernsehen: Eine neue Dimension der Medienvielfalt, Heidelberg. 